\title{
Postnatal Care within Six Hours Following Delivery at Two Selected General Hospitals of Zambia-Mothers' Experiences
}

\author{
Muleya Mutinta Crecious, Mwape Lonia, Katowa-Mukwato Patricia, Maimbolwa Margaret \\ University of Zambia, School of Nursing Sciences, Lusaka, Zambia \\ Email:cmmuleya@gmail.com, loniamagolo@gmail.com, patriciakatowamukwato@gmail.com,mmaimbolwa@yahoo.com
}

How to cite this paper: Crecious, M.M. Lonia, M., Patricia, K.-M. and Margaret, M. (2018) Postnatal Care within Six Hours Following Delivery at Two Selected General Hospitals of Zambia-Mothers' Experiences. Open Journal of Nursing, 8, 355-371. https://doi.org/10.4236/ojn.2018.86029

Received: May 16, 2018

Accepted: June 18, 2018

Published: June 21, 2018

Copyright (c) 2018 by authors and Scientific Research Publishing Inc. This work is licensed under the Creative Commons Attribution International License (CC BY 4.0).

http://creativecommons.org/licenses/by/4.0/

\begin{abstract}
Background: The days and weeks following childbirth (the postnatal period or puerperium), are a critical phase in the lives of mothers and new-born babies. The most vulnerable time for both is during the few hours and days after birth. The period places major demands on the physiological processes of mother and new-born as they adapt the changes of pregnancy and intrauterine life respectively. However, this is the most neglected time for the provision of quality services. Postnatal care is an integral part of the midwife's role in providing care and support to the individual mother and her baby. Postnatal care encompasses aspects of observing and monitoring the health of the mother and her baby, as well as offering support and guidance in breastfeeding and parenting skills. Aim of the study: The aim of the study was to explore the experiences and expectations of mothers concerning care during the immediate postnatal period. Methods and materials: A qualitative approach was utilised to collect data from mothers in their immediate postnatal period using recorded in-depth interviews. A total of thirty (30) mothers were interviewed from two general hospitals. Thematic content analysis was used to analyse the data. Findings: From the study, three main themes emerged; inadequate physical examination, information needs and professional support, and varied staff attitude. The findings of the study have highlighted the inadequacies that are still there regarding immediate postnatal care. Conclusion and recommendations: It can be concluded that mothers have a lot of needs and expectation during this period which are usually not met. One most important conclusion is the lack or poor information given to the women regarding the care of the new-born and subsequent care. This could be one of the reasons mothers do not come back for the subsequent postnatal visit. There is an evidence of poor quality of postnatal care being offered to women during the immediate postnatal period. There are also some negative experiences that postnatal mothers have had and these have led them to being un-
\end{abstract}


satisfied with the care they receive during the immediate postnatal period. However, despite all the above, there is still room for improving the care given during this time. This can help reduce maternal and neonatal morbidity and mortality.

\section{Keywords}

Postnatal Care, Immediate Postnatal Care, Mothers, Experiences, Expectations

\section{Introduction}

The postnatal period-defined here as the first six weeks after birth-is critical to the health and survival of a mother and her new-born [1]. The WHO states that the Post natal period begins immediately after the birth of the baby and extends up to six weeks (42 days) after birth. This is the period and the individual require physical, social, psychological, support. It is during this period that changes in the anatomy, physiology and biochemistry which had occurred during pregnancy and labour return to the pre-gravid state. The mother has to adapt to motherhood and this adjustment can be a challenge [2].

Postnatal care (PNC) is an integral part of the midwife's role in providing care and support to the individual woman and her baby. PNC encompasses aspects of observing and monitoring the health of the mother and her baby, as well as offering support and guidance in breastfeeding and parenting skills [3]. The WHO [4] gives a guideline regarding content, timing, place, and providers of routine PNC. In Zambia PNC is done at six hours, six days and six weeks after delivery in a health institution. The aim of the study was to explore the experiences and expectations of women concerning care during the immediate postnatal period.

\section{Background}

The days and weeks following childbirth, (the postnatal period or puerperium), are a critical phase in the lives of mothers and new-born babies. The most vulnerable time for both is during the few hours and days after birth [4]. The period places major demands on the physiological processes of mother and new-born as they adapt the changes of pregnancy and intrauterine life respectively. However, this is the most neglected time for the provision of quality services. This may be because midwives are usually looking forward to the delivery of a live baby, and once this occurs, little attention is paid to both the mother and the new-born. Consequently, lack of appropriate care during this period could result in significant ill health, disability and even death of the mother or new-born [5].

According to the WHO, most of the maternal and new-born deaths occur within the first 24 hours after birth. Labour, birth and the immediate postnatal period are the most critical for new-born and maternal survival. Unfortunately, 
the majority of mothers and new-borns in low- and middle-income countries do not receive optimal care during these periods [4].

The latest Zambia Demographic and health survey indicate that, maternal mortality is still high at 398 maternal deaths per 100,000 live births while neonatal death stands at 24 per 1000 live birth. Evidence has shown that, a big number of these maternal and neonatal deaths occur during the first 24 hours and days after delivery with postpartum haemorrhage being an important cause [6] [7]. Therefore, prompt postnatal care is important for both the mother and the child to treat complications arising from the delivery, as well as to provide the mother with important information on how to care for herself and the new born. However literature alerts that care during this period is not adequate as shown by the $\mathrm{CSO}$, [Zambia], $\mathrm{MOH}$, [Zambia] and ICF International [7]. Immediate postnatal care is very important as this is the time the mother is and her baby should be assessed for any complications. According to the 2014 Zambia Demographic and heath survey, the proportion of mothers seeking postnatal care from professionally trained personnel was still very low and the (ZDHS) [8] revealed that $51 \%$ of women received no care at all. However, 39 percent received a postnatal check-up within two days of delivery. Nine percent of the women had a check-up 3 to 41 days after delivery. Young mothers and mothers who gave birth to their first child (41 and 49 percent, respectively) are more likely to go for postnatal care within the first two days after giving birth, compared with older mothers age 35 - 49 and mothers with sixth or higher order births (31 and 30 percent, respectively). Therefore, based on these gaps, strengthening the immediate postnatal care would help identify some complications that mothers and new-borns might have. This study therefore sought to investigate the postnatal care experiences and expectations of women delivering at two general hospitals (Kabwe General Hospital and Lewanika General Hospital) in Central and Western Provinces of Zambia respectively.

There hasn't been so much concern about the immediate postnatal care and the study might reveal critical issues which may hinder postnatal mothers from coming back for subsequent postnatal check-ups. The first contact made with the midwife/health care provider could be influencing the subsequent postnatal visits by mothers. As it has shown from the recent demographic and health survey, very few mothers come back for postnatal check-up [7]. Therefore this study might bring out the factors that hinder women from coming back for subsequent postnatal care. It is also hoped that Information generated from the study will help policy makers and health care provider design strategies that will improve postnatal care provision.

\section{Methods}

\subsection{Study Design}

The aim of this study was to explore the experiences of the postnatal mothers concerning a phenomenon. The goal was to understand rather that to predict the 
subjective dimentions of human experiences.Accroding to Creswell [9] phenomenological research helps the researcher to identify the essence of human experiences concerning a phenomenon as described by the participants in the study. Phenomenology helps to re-examine the experiences that may be taken for granted. Phenomenology has been found to be useful in nursing and midwifery as it helps understand people and sympasize with them. According to Laverty [10] disriptive phenomenology is good at reaching the true meaning through engaging in re-examining those taken for granted experiences and perhaps uncover new and/or forgotten meanings.

\subsection{Study Setting}

The study was conducted at two General Hospital of Zambia respectively. The study settings were chosen because of low postnatal care within the first six hours following delivery (Central province-33.8\% and Western Province-34.8\%). The two hospitals were chosen because they are provincial centres for the two respective provinces and they may represent a larger population of the provinces and have a higher number of deliveries. The data was collected over a period from May to August 2017 from the two study sites.

\subsection{Study Population and Sampling Techniques}

The study population for this study were postnatal mothers who were within the first 6 - 24 hours of the postpartum period. A purposive sampling technique was utilised for this study. Only mothers who had delivered from within the two study sites (Kabwe and Lewanika general Hospitals) were included in the study. Postnatal mothers who had a normal delivered from the two General Hospitals and within the first six hours of delivery and were willing to participate in the study. Postnatal mothers who had still births were excluded to avoid psychological trauma and those who were referred from clinics after delivery were excluded in the study.

\subsection{Sample Size Determination}

The sample size was determined using the principle of data saturation. Tordes and Holloway [11] states that the researcher continues to collect data until no new findings emerge (saturation).However, because there were two site for this study, approximate numbers were allocated for each site as saturation can be reached at one site. Crouch \& McKenzie [12] and Guest et al. [13] suggest that saturation often occurs around 12 participants in homogeneous groups and therefore a minimum of 15 participants were interviewed for each of the sites.

\subsection{Data Collection}

In phenomenological research, the classical source of data is through in-depth discussion between the researcher and informant. Data from postnatal mothers within six hours of delivery were collected using in-depth interviews with a tape 
recorder. Time of interviews ranged from 12 minutes to 40 minutes. Few notes were taken from the patient files to supplement the information given. The in-depth interviews were conducted in a private room for privacy and to make the participant comfortable. Demographic characteristics were obtained. A broad question was asked to the mothers to allow them explain their experience of care. The broad question was "what has been your experience of the care that you have received since you delivered". Besides the broad question, follow up/ probing questions were asked to gain a deeper understanding of their experiences. Some of the probing questions asked included: Did you have a full physical examination done? Have you been given enough information that you needed? Have your expectations been met?

\subsection{Data Analysis}

For this study, thematic analysis has been chosen based on the fact that the method helps interpret that data to come up with meaningful themes. Thematic Analysis is also helpful in detecting and identifying some factors or variables that can help understand the information provided by the participants [14] [15]. Six-phase process according to Braun and Clarke [16] was used and this involved: Familiarization with the data followed by reading and re-reading the data, to become immersed and intimately familiar with its content. Coding was done and later identification of themes. Reviewing of themes with their data sets was done which was followed by defining and naming of themes. The final stage was writing up the report in the context of the narratives as given by the participants.

\subsection{Ethical Approval}

Ethical approval was obtained from the University of Zambia Biomedical Research Ethics Committee and the National Health Research Authority. Women who agreed to participate in the study provided a written consent after they were provided with enough information regarding the study.

\section{Findings}

\subsection{Demographic Characteristics of Participants}

In total 30 postnatal mothers were interviewed between the period May to August 2017 from the two study settings (15 participants for Kabwe and 15 participants for Lewanika General Hospital). Some of the characteristics of the participants are as indicated in Table 1.

As can be noted, the participants' age range was between 15 and 45 years. Most (12/70\%) of the participants interviewed were married. As regards to their educational level, $60 \%$ had attained secondary school education and only $10 \%$ had tertiary education from all the two study centers. Forty percent $(40 \% / 12)$ of the women were primipara, while the other $60 \%$ was distributed between Para 2 to Para 6. Another point to note is that majority (94.4\%) of the women interviewed 
Table 1. Participants' demographic characteristics.

\begin{tabular}{|c|c|c|}
\hline AGE RANGE IN YEARS & FREQUENCY & PERCENTAGE \\
\hline $15-20$ & 5 & $16.7 \%$ \\
\hline $21-25$ & 9 & $30 \%$ \\
\hline $26-30$ & 5 & $16.6 \%$ \\
\hline $31-35$ & 6 & $20 \%$ \\
\hline $36-40$ & 1 & $3.3 \%$ \\
\hline \multirow[t]{2}{*}{$41-45$} & 3 & $10 \%$ \\
\hline & \multicolumn{2}{|l|}{ EDUCATIONAL LEVEL } \\
\hline PRIMARY & 9 & $30 \%$ \\
\hline SECONDARY & 18 & $60 \%$ \\
\hline \multirow[t]{2}{*}{ TERTIARY } & 3 & $10 \%$ \\
\hline & \multicolumn{2}{|l|}{ MARITAL STATUS } \\
\hline SINGLE & 9 & $30 \%$ \\
\hline MARRIED & 21 & $70 \%$ \\
\hline DIVORCED & 0 & \\
\hline \multirow[t]{2}{*}{ WIDOWED } & 0 & \\
\hline & \multicolumn{2}{|l|}{ PARITY } \\
\hline 1 & 12 & \\
\hline 2 & 05 & $16.7 \%$ \\
\hline 3 & 05 & $16.6 \%$ \\
\hline 4 & 04 & $13.3 \%$ \\
\hline 5 & 03 & $10 \%$ \\
\hline 6 & 01 & $3.3 \%$ \\
\hline
\end{tabular}

had full term deliveries (36 weeks and above up to 40 weeks gestation) and only $6.6 \%$ had premature deliveries.

\subsection{Women's Experiences}

From the interviews conducted, the main themes that emerged were; inadequate provision of physical examination, information needs, and varied staff attitude in the postnatal ward. Women, especially nulliparous women had some expectations as they were planning for a hospital delivery.

\subsubsection{Inadequate Provision of Physical Examination}

The theme of physical examination not being done to women during early postnatal period kept recurring from almost all mothers interviewed. It was clear 
from some of the mothers that they felt that they needed to be examined. For example one participant who felt they needed an examination had this to say.

No physical examination was done on me. Only temperature and Blood pressure were done. Nurses should not assume all is well. Things should be done the way they should be. If there is need for physical examination, it should be done. Like for me I had severe abdominal pain but I was not examined or given any pain killer. When I asked they said it happens after delivery (Nulliparous mother/tertiary education).

Another participants also felt the need to have an examination done one her because she had lacerations on the private part following delivery and she needed to know how the laceration was.

"No, they didn't do that. They haven't examined us yet. They only measured BP and temperature. Am not sure if they examined my private parts. I had a laceration but not sure if they examined it. Even the baby hasn't been examined from head to toe." (Nulliparous/secondary)

"After that they took me to the bed where they checked my temperature and BP. No physical examination was done on both me and the baby. Probably because it was at night that's why it was not done." (Multiparous/secondary education)

"No they didn't. They only checked my BP and temperature. The baby was placed on the weighing scale but am not sure what else was done on him because I was in so much pain and I might not remember what else was done on him." (nulliparous/secondary)

The finding show that generally, midwives only check blood pressure and temperature during the postnatal period and some women take this as the postnatal examination which shows that some women did not know what examination was supposed to be done during that period.

"Yes, I was examined. After I delivered they examined me, they checked the $\mathrm{BP}$ and the temperature. General body examination was not done. The baby's temperature was checked. I think that's all they did." (nulliparous/primary education)

Another mother had this to say;

"They then checked my temperature and BP and that's how I slept well. In the morning around $04 \mathrm{hrs}$, they came to check my temperature and BP noting how well I had slept. They also examined the baby's temperature." (Multiparous/secondary education)

"They checked my temperature, BP and even touched my abdomen after I delivered. They also checked for blood loss to make sure I haven't bleed a lot. The baby was put on the weighing scale and the temperature was checked." (multiparous/primary) 
Some mothers felt that the examination was fully done and were happy with it although they did not know exactly what the midwife was looking for.

"Yes she did, she first checked my breasts, checked how they are responding to the baby, if am able to hold the breast nicely. She checked my blood flow if am bleeding a lot or not and even told me how not to have pains in the abdomen. She didn't examine the abdomen but she told me what to do. She examined the baby thoroughly although she didn't tell me what she was looking for." (Nulliparous/Secondary education)

Despite having a lot of mothers mentioning that they were not examined, some mothers indicated that they received a full physical examination from the midwives during the early postpartum.

"It was done in postnatal ward before discharge and the findings were communicated. They also did physical examination on the baby concentrating on the umbilical stump." (multiparous/tertiary)

"Both I and the baby were examined from head to toe. They also asked me about any bleeding through the vagina. The baby's umbilical stump was also checked." (multiparous/primary)

"They examined me and the baby from head to toe particularly the eyes, legs and the vulva." (multiparous/secondary)

\subsubsection{Information Needs and Professional Support}

Some postnatal mothers felt that they were not adequately informed of what was happening to them or their babies during the early postpartum. Information that they need may be varied. For some, they needed to be communicated to of their health as assessed by the midwife/care provider and for others it was information regarding how they will take care of the baby after discharge or any follow up.

"In terms of information, when I asked, I was only told premature babies some tend to take long to stabilise. They don't explain to you why premature babies tend to perform like this. Not telling me the reason why she is doing all that. The reason why the temperature keeps dropping...The reason why she is not breathing to well." (Nulliparous/tertiary)

"They examined me and the baby after delivery but results were not communicated." (multiparous/primary)

For a first time mother their need for information may differ from the multiparous mother who has been through the process before. These may seem to expect a lot of information from the health care provider on how they should behave now as a mother. These are some of the voices of first time mothers;

“...Nurses should not assume all is well... I think nurses should be giving information to mothers especially first time mother so that they know what to expect." (Nulliparous/ tertiary education) 
"No information was given to me regarding care of the baby and even myself and even when to come for reviews." (Nulliparous/tertiary)

"When first time mothers come they should be instructed on exactly what to do and not yell at them. They should have a one on one talk telling the mothers exactly what to do, 'you have to sleep like this.' After delivery we should be told about family planning issues, how to breastfeed. I haven't been told about reviews yet but was told they have another lecture for me but I haven't gone there yet. I heard others being told about the reviews though." (Nulliparous/secondary)

"She examined the baby thoroughly although she didn't tell me what she was looking for." (Nulliporous/secondary)

However, another finding is that some health care providers were able to explain to the mother regarding the findings after examination and some information pertaining to any follow up visit that the mother was to make following discharge.

"They examined me and the baby immediately after delivery. They communicated to me the need for me to remain in hospital as I was pale and weak." (Multiparous/secondary)

"mmmmm... yes, I think they are doing a good job. They even explained to me about the postnatal reviews and even the vaccinations that the baby is to receive." (Multiparous/secondary)

"Yes... to me, whatever is being done is alright. They have even given me information about review dates for both me and baby. So I know when to come for my check-up." (Nulliparous/primary)

"They told me to come for reviews after six days and told me to be sitting in cold water in the morning after bathing because they said I have some wounds which I sustained during delivery." (Nulliparous/secondary)

\subsubsection{Varied Staff Attitude in the Postnatal Ward}

Although most women acknowledged that the care providers were few and busy, this should not make them apprehensive. They need to attend to the needs of the clients as this is their core duty without being upset. Women experienced varied staff attitudes from the staff; others good and positive attitude while other negative attitudes.

Some women had this to say following and interaction with the staff;

“...some nurses/ midwives are not good at all... they need to improve on care, in terms of handling the clients. Some nurses are harsh on the clients. They should always listen to clients concerns and appropriately attend to their needs. After all these nurses are paid for their work." (Multiparous/secondary)

"well... some nurses are good you are free to interact with them and can even ask questions and they will answer you nicely but some of them you are even afraid of asking them, since them they know they don't have the 
patience to answer you, some are bad, they are sulky. The attitudes are bad, they have to change." (Multiparous/secondary education).

Another nulliparous woman who felt that some staff are good and others have a bad attitude expressed herself in this way.

"You know... these people save lives of many people, so they should have a heart of helping others. What I mean is that... they should put passion in what they do and whenever we ask something, because we can't ask a question if you are not worried. It's the fear and the worry that makes us ask a lot of questions. But certain people... yes like the one who was in charge in the night was very nice. So if they can allow us to talk to them in that manner. Like they hear your views and they answer you back nicely." (Nulliparous/tertiary)

In some cases women however expressed that the staff had good attitude in caring for them and were happy with the care they received.

"From the time I delivered my experience was good without any problem. The nurses took very good care of me and the baby. They supported me and were very helpful with dressing the baby while here in the postnatal ward." (Multiparous/secondary)

"hmmmmm... generally all is well, I have seen a lot of improvements, the hospital is clean and the toilets are equally clean. The nurses are also doing a good job. They are taking good care of us and they are approachable." (multiparous/secondary education)

"I was taken good care of. They even gave me warm porridge. The midwives were so good to me, they never shouted at me or said anything bad. They just showed us the way to do things for instance that I have to wash my breasts before breastfeeding him." (Nulliparous/secondary education)

\subsection{Women's Expectations}

When women go to deliver at the health facility, they have expectation which may vary according to their previous experiences and others according to what they have heard about health facilities and health care providers. Some women had heard that nurses and midwives are bad and this is what others had to say;

"Contrary to the negative views I used to hear that nurses are harsh, what I found was different. Everyone was good to me. I think they are good..." (Nulliparous/tertiary education)

"I never expected to be well received as they did. I expected to find ill hearted nurses that would shout at me as I heard from friends. But... ok, it was different." (Nulliparous/primary education)

"mmm... honestly speaking there is an improvement in the care of women from the last time I came to deliver. Last time I came to deliver the nurses would just help you deliver then remove the placenta then ask you to move to the bed, but now they clean you and examine you to make sure there is 
no bleeding and the baby is wrapped for you and they even help carry the baby and your luggage to the bed. Even as you move to the bed all is well. They also teach us on several issues. The hospital is indeed working." (Multiparous/ Secondary education)

Some women opted to deliver at the hospital because they expected good care from trained personnel. This means that their expectation were to receive good care. Some of them had this to say;

"I expected to receive care from the nurses as they are well trained to handle even the complications unlike at home where they are no skilled people to help. They did very well without any mistakes." (Multiparous/primary)

"I was supposed to go to the clinic to deliver but I chose to come to the hospital because they offer good care here at the hospital and my expectations were met." (Multiparous/secondary education)

"I expected to receive good care and that is what Ihave received." (Nulliparous/secondary education)

\section{Discussion}

This study aimed at exploring the experiences and expectation of women during the early postpartum period. This is an important period of time for the survival of both the mother and the new-born [4]. An important part of maternity service provision is the care provided by midwives in the immediate postpartum period. Evidence has always suggested that postpartum morbidity and its impact on women's health after childbirth is an area of genuine concern.Despite efforts to improve care provision to mothers and their new-born babies, there is little paid to mothers' views and experiences of their postnatal care, particularly on the postnatal ward, their expectations of care or what they found to be helpful [17].

Experiences of health care are subjective and each individual will have their own views concerning their perception and overall general experience. Research has shown that, in general, women are satisfied with prenatal care [10] [18] [19] but they are consistently less satisfied with postpartum care [20] [21].

The study participants in this current were varied in terms of age, marital status, parity and educational status. Not only that, but the data was collected from two different settings. This means that their experiences and expectations could also vary in some way. However, despite having two different sites of study, the experiences and expectations are similar in all women.

From the study, three major themes across the two settings emerged; inadequate physical examination, varied staff attitude and information needs and professional support. For easy following and understanding the discussion will be done according to the themes.

\subsection{Inadequate Physical Examination}

The content of immediate postnatal care has continuously been reviewed and has changed over the years. With so many influencing factors, attention to the 
mother has slowly shifted to the new-born [22] and physical examination for mother is slowly being neglected, but still conducted in postnatal wards in other countries [23]. According to the WHO postnatal guidelines [24] postpartum women should have regular assessment of vaginal bleeding, uterine contraction, fundal height, temperature, pulse blood pressure routinely during the first 24 hours starting from the first hour after birth. Voiding should also be monitored as this can lead to postpartum haemorrhage. However, from the study, the findings show that some women did not receive a full physical examination within the early postnatal period. It is also worth noting that some women did not understand or rather know that they were to receive a physical examination during this period. This was seen from responses from the mothers who only had vital signs done on them and they called it physical examination. The lack of postnatal examination compromises the care that women receive and therefore putting them at risk of developing complication which could have been identified. These results are similar with Dlamini et al. [25] where sub-standard postnatal care was provided to women with a high percentage of them not undergoing physical examination in the early postnatal period. This is the time where about $60 \%$ of maternal deaths occur [1]) and therefore quality postnatal care can help identify some of the danger signs. Dlamini et al. [25] who focused on immediate postnatal care of HIV infected women alluded to the fact that quality immediate PNC to HIV infected mothers can reduce the risk of complications and deaths as well as promote the health of the mother and the baby.

\subsection{Information Needs and Professional Support}

All women regardless of parity require information about their health and the health of their neonate. A common theme from this study was poor information delivery from the health care providers. Women especially the primi-parous who are experiencing delivery for the first time depend on the support given to them by the health care providers and also rely on the information they are given regarding their own acre and how they are to take care of the neonate. This finding seems to be in agreement with an Australian study which revealed that there was poor information giving by the midwives to the postnatal mothers [26]. This lack of information could contribute to women not coming back for future postnatal check-up because they are not given adequate information on the value of postnatal check-up.

As noted by another previous study [27] poor communication and information giving by care providers had a negative impact experience on the part of the mother. Similarly, a meta-synthesis conducted which included nine (9) qualitative studies examining women's perception of the care during the post-partum period also revealed that there is lack or poor information giving by the health care provider including midwives [28]. Information giving concerning what is happening to them and professional support relieved anxieties of mothers. Much of the information and support postnatal mothers (especially new mothers) in 
this study required is about care of the neonate, post-partum prescribed medication breastfeeding support, danger signs and completion of postnatal check-up which is similar to other studies [29] [30] [31]. On discharge from hospital, women have reported: that they lack confidence, particularly for breastfeeding; are unprepared for physical or psychosocial problems they may encounter; and have little follow-up or community support [32]. This is as a result of poor information giving and lack of professional support and advice about baby care. Midwives were not readily available to give help or advice about baby feeding, support and advice about baby care, mother's health and recovery, and preparing to go home. Some women have attributed this to shortages of midwives who are too busy with other ward routines. Similarly, Ellberg et al. [33] also noted that parents found the help and support from the care givers/midwives insufficient, and they felt lonely and abandoned in their new role as mothers. Mothers expressed dissatisfaction over the care and they sometimes they felt as if they were in the way of the staff and had to manage themselves or seek help from fellow clients. Although information needs and support are important to all women first time mothers expressed concern over the short hospital stay following delivery because they would not have had enough time to be with the care giver for support. They felt that they needed more support than those who had delivered before. This is similar to Foster et al. [34] findings where primi-parous women felt there was little time given to them to receive more information on how they were going to care for the baby. The period of transition to motherhood and parenting was a fearful one to them and they needed more time to be with the care givers to get more information and support. On the contrary, women in a Swedish study indicated that they normally received adequate information during the immediate postpartum period [35] and this can be a lesson learn to help the women.

\subsection{Varied Staff Attitude in the Postnatal Ward.}

From the findings, Women experienced varied staff attitudes from the staff; others good and positive attitude while other negative attitudes. While some midwives/caregivers were described as very good and caring, others were being described as insensitive and with bad attitude towards women. According to Rudman \& Waldenström [36], another experience women have is the fact that some caregivers have less contact with women during the immediate postnatal period, not showing concern about the mother's feelings, and wellbeing including the wellbeing of the baby. Mothers view this as being insensitive and unfriendly. Although some women noted that the negative and an unwelcoming attitude was associated to staff shortages and lack of time to share with the women this however should not be an excuse for bad attitude towards women. Women feel they should have passion and a heart for caring as they are serving the clients. Similarly Beake et al. [30] reported women experiencing certain attitudes from care givers and the negative impact it has on their experiences. An- 
other previous study by Ong et al. [37] highlighted the perception of women for lack of knowledge in various aspects including infant care. This therefore entails that mothers need more information and professional support regarding care of the new-born before they are discharged.

On the contrary in this study, some women felt that some staff had good attitude and gave them enough support during the immediate postnatal period and were happy with the care they received despite the critical shortage of midwives. It is therefore important that midwives/care givers display good attitudes towards the clients as this can make women shun the services.

\subsection{Women's Expectation of Immediate Postnatal Care}

Regarding postnatal mothers' expectation of immediate postpartum care, women have various expectations as individuals. Others from previous experiences expect to be well treated while in the same vain others expect to be ill-treated. When they decide to deliver at a health institution, they want their expectations to be met as they go back home. In this study some women never expected to be well treated, but contrary to their negative expectation, they found that care givers were caring and their expectation of good care was met. However, some women's expectations of good and quality care were not me. This could have been to poor information giving from the care givers and inadequate examination. This can have an impact on the utilisation of delivery services by women if their expectations are not met.

\section{Conclusion}

It is evident that mothers have a lot of needs and expectation during this period which are usually not met. One most important conclusion is the lack or poor information given to the women regarding the care of the new-born and subsequent care. This could be one of the reasons mothers do not come back for the subsequent postnatal visit. There are some evidences of poor quality of postnatal care being offered to women during the immediate postnatal period. There are also some negative experiences that women have had and these have led them to being unsatisfied with the care they receive during the immediate postnatal period. Some of the experiences are related to the parity of the woman as the primi-parous women feel they need more care that those who have delivered before. However there is satisfaction reported among women which can be further improved to encourage women to utilise maternity services in Zambia and other countries.

\subsection{Recommendations}

Based on the findings of this study, the authors are making recommendations that the Policy makers (Ministry of Health) need to offer refresher or in-service training regarding the postnatal care content and its importance to all care providers working in maternity units. The Nursing and Midwifery training institu- 
tions also need to strengthen the curriculum in teaching learners to provide quality postnatal care. It is also important to educate the mothers regarding the care they are supposed to receive at any level for them to question non provision of this care by the care providers. There is need for further exploration of mothers' experiences in remote areas to determine the differences in geographical location.

\subsection{Study Limitations}

The author acknowledge the fact that the study was only limited to two sites. However the strength is that the sites are different in terms of geographical location as one was an urban setting while another was peri-urban.

\section{Acknowledgements}

The authors would like to acknowledge the financial support provided by the Norwegian Agency for Development (NORAD) through the NORHED QZA-0848 QZA-MW-13/00032 Grant.

Acknowledgements also go the mothers who participated in this study.

\section{References}

[1] World Health Organisation (2010) WHO Technical Consultation on Postpartum and Postnatal Care. WHO/MPS/10.03, Geneva.

[2] Sellers, P.M. (2007) Midwifery. 9th Edition, Juta, Lansdowne.

[3] Fraser, D.M. and Cooper, M.A. (Eds.) (2009) Myles' Textbook for Midwives E-Book. Elsevier Health Sciences, Amsterdam.

[4] World Health Organisation (2013) WHO Recommendations on Postnatal Care of the Mother and New-Born. World Health Organization, Geneva.

[5] Ronsmans, C., Graham, W.J. and Lancet Maternal Survival Series Steering Group (2006) Maternal Mortality: Who, When, Where, and Why. The lancet, 368, 1189-1200. https://doi.org/10.1016/S0140-6736(06)69380-X

[6] Central Statistical Office (CSO) (2009) ZDHS: Reproductive Health in Zambia. Lusaka

[7] Central Statistical Office (CSO) [Zambia], Ministry of Health (MOH) [Zambia], and ICF International (2014) Zambia Demographic and Health Survey 2013-14. Central Statistical Office, Ministry of Health, and ICF International, Rockville.

[8] Central Statistical Office (CSO) (2007) ZDHS: Reproductive Health in Zambia. Lusaka.

[9] Creswell, J.W. (2007) Qualitative Inquiry and Research Design: Choosing among Five Approaches. Sage, Thousand Oaks.

[10] Laverty, S.M. (2003) Hermeneutic Phenomenology and Phenomenology: A Comparison of Historical and Methodological Considerations. International Journal of Qualitative Methods, 2, 21-35. https://doi.org/10.1177/160940690300200303

[11] Tordes, L. and Holloway, I. (2010) Phenomenological Research. In: Gerrish, K. and Lacey, A., Eds., The Research Process in Nursing, 6th Edition, Wiley-Blachwell, London. 
[12] Crouch, M. and McKenzie, H. (2006) The Logic of Small Samples in Interview-Based Qualitative Research. Social Science Information, 45, 18. https://doi.org/10.1177/0539018406069584

[13] Guest, G., Bunce, A. and Johnson, L. (2006) How Many Interviews Are Enough? An Experiment with Data Saturation and Variability. Field Methods, 18, 24. https://doi.org/10.1177/1525822X05279903

[14] Hatch, J.A. (2002) Doing Qualitative Research in Education Settings. Suny Press, New York.

[15] Creswell, J.W. (2003) Research Design: Qualitative, Quantitative and Mixed Methods Approaches. 2nd Edition, Sage, Thousand Oaks.

[16] Braun, V. and Clarke, V. (2006) Using Thematic Analysis in Psychology. Qualitative Research in Psychology, 3, 77-101. https://doi.org/10.1191/1478088706qp063oa

[17] Singh, D. and Newburn, M. (2001) Women's Experiences of Postnatal Care. National Childbirth Trust, London.

[18] Homer, C.S., Davis, G.K., Cooke, M. and Barclay, L.M. (2002) Women's Experience of Continuity of Midwifery Care in a Randomised Controlled Trial in Australia. Midwifery, 18, 102-112. https://doi.org/10.1054/midw.2002.0298

[19] Biro, M.A., Waldenstrom, U., Brown, S. and Pannifex, J.H. (2003) Satisfaction with Team Midwifery Care for Low- and High-Risk Women: A Randomized Controlled Trial. Birth, 30, 1-10. https://doi.org/10.1046/j.1523-536X.2003.00211.x

[20] Waldenström, U., Rudman, A. and Hildingsson, I. (2006) Intrapartum and Postpartum Care in Sweden: Women's Opinions and Risk Factors for Not Being Satisfied. Acta Obstetricia et Gynecologica Scandinavica, 85, 551-560. https://doi.org/10.1080/00016340500345378

[21] Hodnett, E., Gates, S., Hofmeyr, G. and Sakala, C. (2007) Continuous Support for Women during Childbirth. Cochrane Database of Systematic Reviews, No. 2, CD003766. https://doi.org/10.1002/14651858.CD003766.pub2

[22] Hildingsson, I. (2007) New Parents' Experiences of Postnatal Care in Sweden. Women and Birth, 20, 105-113. https://doi.org/10.1016/j.wombi.2007.06.001

[23] McLachlan, H., Forster, D., Yelland, J., Rayner, J. and Lumley, J. (2007) Is the Organization and Structure of Hospital Postnatal Care a Barrier to Quality Care? Findings from a State-Wide Review in Victoria, Australia. Midwifery, 24, 358-370. https://doi.org/10.1016/j.midw.2006.10.006

[24] World Health Organisation (2014) WHO Recommendations on Postnatal Care of the Mother and Newborn. World Health Organization, Geneva.

[25] Dlamini, B.R., Ziyane, I.S. and Gule, W.P. (2017) The Quality of Immediate Postnatal Care in Health Facilities in Swaziland: Experience of Postnatal Mothers. Journal of AIDS and Clinical Research, 8, 672. https://doi.org/10.4172/2155-6113.1000672

[26] Fenwick, J., Butt, J., Dhaliwal, S., Hauck, Y. and Schmied, V. (2010) Western Australian Women's Perceptions of the Style and Quality of Midwifery Postnatal Care in Hospital and at Home. Women and Birth, 23, 10-21. https://doi.org/10.1016/j.wombi.2009.06.001

[27] Bhavnani, V. and Newburn, M. (2010) Left to Your Own Devices: The Postnatal Experiences of 1260 First Time Mothers. The National Childbirth Trust, London.

[28] Correa, M.S., et al. (2014) Women's Perception Concerning Health Care in the Post-Partum Period: A Meta-Synthesis. Open Journal of Obstetrics and Gynecology, 4, 416-426. https://doi.org/10.4236/ojog.2014.47062 
[29] Almeida, M.S. and Silva, I.A. (2008) Women's Needs in Immediate Puerperium in a Public Maternity in Salvador, Bahia, Brazil. Revista da Escola de Enfermagem da USP, 42, 347-354. https://doi.org/10.1590/S0080-62342008000200019

[30] Beake, S., Rose, V., Bick, D., Weavers, A. and Wray, J. (2010) A Qualitative Study of the Experiences and Expectations of Women Receiving In-Patient Postnatal Care in one English Maternity Unit. BMC Pregnancy and Childbirth, 10, 70. https://doi.org/10.1186/1471-2393-10-70

[31] Bailey, S. (2010) Postnatal Care: Exploring the Views of First-Time Mothers. Community Practitioner, 83, 26-29.

[32] Brown, S.J., Davey, M.A. and Bruinsma, F.J. (2005) Women's Views and Experiences of Postnatal Hospital Care in the Victorian Survey of Recent Mothers 2000. Midwifery, 21, 109-126. https://doi.org/10.1016/j.midw.2004.09.006

[33] Ellberg, L., Högberg, U. and Lindh, V. (2010) "We Feel like One, They See Us as Two": New Parents' Discontent with Postnatal Care. Midwifery, 26, 463-468. https://doi.org/10.1016/j.midw.2008.10.006

[34] Forster, D.A., McLachlan, H.L., Rayner, J., Yelland, J., Gold, L. and Rayner, S. (2008) The Early Postnatal Period: Exploring Women's Views, Expectations and Experiences of Care Using Focus Groups in Victoria, Australia. BMC Pregnancy and Childbirth, 8, 27. https://doi.org/10.1186/1471-2393-8-27

[35] Hildingsson, I.M. and Sandin-Bojö, A.K. (2011) "What Is Could Indeed Be Better"-Swedish Women's Perceptions of Early Postnatal Care. Midwifery, 27, 737-744. https://doi.org/10.1016/j.midw.2010.04.007

[36] Rudman, A. and Waldenström, U. (2007) Critical Views on Postpartum Care Expressed by New Mothers. BMC Health Services Research, 7, 178. https://doi.org/10.1186/1472-6963-7-178

[37] Ong, S.F., Chan, W.C.S., Shorey, S., Chong, Y.S., Klainin-Yobas, P. and He, H.G. (2014) Postnatal Experiences and Support Needs of First-Time Mothers in Singapore: A Descriptive Qualitative Study. Midwifery, 30, 772-778. https://doi.org/10.1016/j.midw.2013.09.004 